istic of the substance under examination. (In many instances microchemical tests are also of value for the purpose of verification.)

SUMMARY.

Attention has been called to the application of optical-crystallographic methods for the identification of crystallizable chemical salts in insecticides and fungicides. The author has found the use of such methods of value in many instances and has attempted to outline a simple method of procedure particularly suitable for microanalysts who have not had extensive training in crystallography and mineralogy.

No attempt has been made to go into detail concerning crystallographic and optical concepts, it being left to the reader to avail himself of these in works dealing primarily with petrographic methods.

\title{
THE DELICACY OF THE U. S. P. TESTS.
}

\section{BY JOSEPH ROSIN.}

By "delicacy" is here understood the quantity or proportion of the impurity examined for which will just fail of being detected. It is practically synonymous with "sensitiveness" and the two terms are used here interchangeably.

It is almost needless to state that in making the U. S. P. tests the directions of the Pharmacopoeia were closely followed. In several instances, however, deviations from the Pharmacopoeial instructions were necessary, and these are noted under the respective tests. Where the U. S. P. directions are not sufficiently explicit, the more explicit details given in the U.S.P. for testing other similar products for the same impurities were observed, or the established good practice in carrying out tests of this character was followed.

The materials used were the purest obtainable, or they were specially prepared. If they were not entirely free of the impurities to be tested for, the latter were determined and a correction applied in the final calculations of the results.

The method of procedure was the one generally employed in an investigation of this character. Solutions or mixtures of the pure material with varying proportions of the impurity to be tested for were subjected to the U. S. P. test or to the proposed test.

Before proceeding with the presentation of the results it will be well to note that in instances where the U. S. P. allows a slight turbidity or opalescence in the test, the results recorded are necessarily arbitrary, because, as it has been pointed out by others, the meaning of "slightly turbid" or "opalescent" is subject to various interpretations by observers. Even in the more definite tests where no manifestation of the presence of the impurity is allowed, somewhat divergent and occasionally very divergent results are obtained, because of differences in the manipulation of the test. For instance, in the majority of the U.S. P. tests it is simply directed to add the reagent to the solution or substance under examination without stating whether it should be mixed. True, the accepted practice is to mix the solution, but it is also true that not all mixings are equally effective. This is particularly the case when the quantities tested for are small and the time limit for the reaction is short. Other details in the manipulation, the diameter 
of the test tube in which the test is made, as well as external conditions, such as illumination, temperature, etc., have a more or less definite bearing on the sensitiveness of the tests.

In this paper are recorded the results obtained with official acids. The sensitiveness of the U. S. P. tests for impurities in other official products is also being investigated and will be reported in due course. The percentage figures for sensitiveness given in this paper refer to ions.

\section{ACETPHENETIDIN.}

Acetanilid.-Material for this test was prepared by dissolving recrystallized acetphenetidin U. S. P. with varying proportions of acetanilid in a minimum quantity of hot alcohol and evaporating to dryness on a water-bath. The residue was powdered and well mixed.

The U. S. P. directs:

"Boil about $0.1 \mathrm{Gm}$. of acetphenetidin with $10 \mathrm{Cc}$. of water until dissolved, cool the solution, filter it, and add bromine T.S. to the filtrate, drop by drop, with agitation after each addition, until the solution remains permanently yellow; neither turbidity nor precipitation is produced."

The delicacy of the bromine-acetanilid reaction is approximately 1 in 5000 . To attain this degree of sensitiveness it is necessary to let the mixture stand 15 minutes or longer before a turbidity will be noticeable. In the U. S. P. test it is understood that observation is to be made in 5 minutes after the addition of the bromine water. With this time limit the sensitiveness of the reaction is not greater than about 1 in 2000 . Based on these facts the U. S. P. test should be delicate to about 4 to $5 \%$. Experiments have proved this to be correct.

It is also quite evident that if a larger quantity of acetphenetidin be used with the same volume of water, the delicacy will be proportionally increased. Using $0.5 \mathrm{Gm}$., the test is rendered sensitive to about $1 \%-\mathrm{a}$ sufficient degree of delicacy for the purpose of the U.S. P.

\section{ACETIC ACID.}

Formic or Sulphurous Acids.--In testing for these impurities the U. S. P. instructs to:

"Supersaturate $5 \mathrm{Cc}$. of the acid with $10 \mathrm{Cc}$. of ammonia water, add $5 \mathrm{Cc}$. of tenth-normal silver nitrate and boil the mixture for one or two minutes; no dark deposit is produced."

The delicacy of this test is about $1.5 \%$ for formic acid or $0.025 \%$ for sulphur dioxide. If, instead of supersaturation, the acid is neutralized with ammonia, which would require about $5 \mathrm{Cc}$, and boiled for 1 minute with $2 \mathrm{Cc}$. of silver nitrate, a delicacy of about $1 \%$ for formic acid is attainable.

Mercuric chloride is indeed a much more sensitive reagent for formic acid or sulphur dioxide than silver nitrate. On boiling $5 \mathrm{Cc}$. of acetic acid with $1 \mathrm{Cc}$. of a saturated aqueous solution of mercuric chloride for 2 minutes, a turbidity is produced when $0.08 \%$ formic acid or $0.001 \%$ sulphur dioxide is present. This test is, of course, too delicate for U. S. P. acetic acid.

ACID BENZOIC.

Cinnamic Acid.-Synthetic benzoic acid and the desired proportions of cinnamic acid were dissolved in a minimum quantity of warm ether, the solution 
allowed to evaporate at room temperature and the residue of the acids powdered and well mixed.

The U.S. P. directions are:

"Warm $0.5 \mathrm{Gm}$. of the acid with $5 \mathrm{Cc}$. of distilled water and $0.5 \mathrm{Gm}$. of potassium permanganate in a loosely stoppered test tube, and place it in a water-bath heated to about $45^{\circ} \mathrm{C}$. for ten minutes. Stopper the test tube tightly and allow it to cool. On removing the stopper, no odor of benzaldehyde is perceptible."

This test is delicate to about 2.5-3\%. A greater degree of sensitiveness can be secured by "dissolving $0.5 \mathrm{Gm}$. of the benzoic acid in $20 \mathrm{Cc}$. of hot water and adding $2 \mathrm{Cc}$. of $\frac{\mathrm{N}}{10}$ potassium permanganate to the hot solution." In the presence of $0.5 \%$ of cinnamic acid, a distinct odor of benzaldehyde will be perceptible.

ACID CITRIC.

Oxalic Acid.-The U. S. P. states:

"An aqueous solution of citric acid (1 in 10) which has been nearly neutralized with am monia water remains clear on the addition of calcium sulphate $\mathrm{T}$. S."

Calcium sulphate solution is not a suitable reagent for the detection of oxalic acid in citric. The degree of its sensitiveness for this test also depends on the quantity used, but the U. S. P. does not indicate how much to use. In applying the U.S. P. test to citric acid to which the equivalent of $7 \%$ of anhydrous oxalic acid has been added, when $5 \mathrm{Cc}$. of calcium sulphate was used, no turbidity was noticeable in 30 minutes. With $10 \mathrm{Cc}$. of calcium sulphate a turbidity was observed in 20 minutes. With $15 \mathrm{Cc}$. of calcium sulphate a slight turbidity was noticeable in 15 minutes. To attain a test delicate to about $0.5 \%$ oxalic acid, the following modification is suggested:

"Ten Cc. of the aqueous solution of the acid ( 1 in 10) is neutralized with ammonia water, then 5 drops of diluted hydrochloric acid added followed by $2 \mathrm{Cc}$. of calcium chloride $T$. $S$. and shaken; no turbidity is produced."

By increasing the amount of calcium chloride to $3 \mathrm{Cc}$, and allowing to stand for one hour, $0.25 \%$ oxalic acid is detectable, but a larger quantity of calcium chloride than this and longer standing will cause precipitation of calcium citrate.

Sulphuric Acid.-The sensitiveness of the U. S. P. test for this impurity is about $0.025 \%$. When more than this amount is present a turbidity will be produced in 5 minutes.

Tartaric Acid.-The U. S. P. directs:

"Heat about $5 \mathrm{Gm}$. of powdered citric acid for 15 minutes on a water-bath with $5 \mathrm{Cc}$. of sulphuric acid in a porcelain dish, which has previously been rinsed with sulphuric acid, keep the mixture protected from dust; no darker color than yellow develops."

Pure citric acid yields with this test an orange-yellow or brownish yellow color, and no darker color was produced when $2-3 \%$ of tartaric acid was present. The fault in the U.S. P. test is that the quantity of sulphuric acid is too small.

The British Pharmacopoeia test for tartaric acid is:

"One Gm. of powdered citric acid mixed with $10 \mathrm{Cc}$. of sulphuric acid in a test tube previously rinsed with sulphuric acid acquires not more than a pale yellow color when kept at a temperature of $90^{\circ}$ for one hour."

This method will detect with a fair degree of certainty about $0.5 \%$ tartaric acid. 
The delicacy of the sulphuric acid test for tartaric acid is proportionate to the temperature at which the mixture is heated. If instead of $90^{\circ} \mathrm{C}$. it is heated for one hour at $100^{\circ} \mathrm{C}$. a delicacy of $0.25 \%$ is attainable. By heating a mixture of $0.5 \mathrm{Gm}$. citric acid with $5 \mathrm{Cc}$. of sulphuric acid in the flame of a Bunsen burner for one minute and comparing the color so produced with that of a blank with pure citric acid, $\mathrm{Hill}^{1}$ detects as little as $0.01 \%$ of tartaric acid. With this process I have been able to confirm unmistakably the presence of $0.02 \%$ tartaric acid.

\section{ACID HYDRIODIC DILUTED.}

Barium.-The U. S. P. test is:

"The addition of one Cc. of potassium sulphate T. S. to $10 \mathrm{Cc}$. of the acid causes no turbidity."

The hydriodic acid available contained a trace of sulphate. The usual method for the determination of sensitiveness was therefore reversed. Ten Cc. portions of the acid were mixed with $1 \mathrm{Cc}$. of potassium sulphate solution and progressive quantities of a standard barium chloride solution added until the quantity required to yield a slight precipitate in 5 minutes was reached. A delicacy of about $0.002 \%$ was thus attainable. Longer standing than 5 minutes increases the delicacy by about $20-30 \%$.

The U. S. P. potassium sulphate T. S. contains $1 \%$ potassium sulphate, corresponding to 0.087 normal. If $1 \mathrm{Cc}$. of half normal potassium sulphate is used the sensitiveness of the test is increased about threefold.

Chloride.-To test for chloride in hydriodic acid the U. S. P. directs:

"Mix $0.5 \mathrm{Cc}$. of diluted hydriodic acid with $10 \mathrm{Cc}$. of distilled water, add $8 \mathrm{Cc}$. of silver nitrate T. S. and $6 \mathrm{Cc}$. of ammonium carbonate T. S., digest the mixture for 10 minutes on a water-bath, cool, and filter. The filtrate, upon supersaturating with nitric acid, does not become more than slightly opalescent."

This test was found to be more sensitive than was anticipated. In the presence of $0.02 \%$ of $\mathrm{Cl}$ a decided turbidity results. Two brands of diluted hydriodic acid examined by the U. S. P. method showed no greater turbidity than corresponds to about $0.01 \%$ of $\mathrm{Cl}$. It appears that $0.02 \%$ of $\mathrm{Cl}$ is an ample allowance for this impurity.

Sulphuric Acid.-In this test the U. S. P. allows a slight cloudiness. It is quite evident that the evaluation of "slight cloudiness" is very difficult, but from several experiments made with this test and submitted to several persons for their opinion, it seems that even a most liberal interpretation of "slight cloudiness" would not permit more than $0.01 \%$ sulphate.

\section{ACID HYDROBROMIC DILUTED.}

Barium.-The delicacy of this test is about $0.005 \%$. As in the case of hydriodic acid, it is increased almost threefold by using half normal potassium sulphate instead of the U. S. P. solution.

Sulphuric Acid.-Here, too, the U. S. P. allows a slight cloudiness and it was shown that as little as $0.01 \%$ produces a very pronounced turbidity.

${ }^{1}$ Pharm J., 84, 245, 1910. Also Allen, "Com. Org. Anal.," Vol. IX, p. 114. 
ACID HYDROCHLORIC AND ACID HYDROCHLORIC DIIUTED.

Sulphuric Acid.-The U. S. P. test excludes more than $0.01 \%$ of sulphate in the diluted acid corresponding to $0.03 \%$ in the stronger acid.

ACID HYPOPHOSPHOROUS AND ACID HYPOPHOSPHOROUS DILUTED.

Barium.-The delicacy of the U. S. P. test for barium in the diluted acid is $0.0035 \%$ corresponding to $0.010 \%$ in the $30 \%$ hypophosphorous acid. It is likewise increased to almost three times as much when half normal of potassium sulphate is used.

NoTE.-Hypophosphorous acid of commerce usually contains some sulphate and therefore cannot contain any barium.

Oxalic Acid.-To test for this impurity the U. S. P. directs to:

"Neutralize the acid with ammonia, filter and add to filtrate calcium chloride; no turbidity should be produced."

Hypophosphorous acid U. S. P. always contains a little calcium; therefore, unless there is more oxalic acid present than is sufficient to combine with all the calcium, the oxalic acid will be entirely precipitated as calcium oxalate and none will be found in the filtrate, even though originally it was present.

With the following test a delicacy to less than $0.01 \%$ as anhydrous oxalic acid in the diluted acid can be attained:

"To $10 \mathrm{Cc}$. of the acid $1 \mathrm{Cc}$. of calcium chloride T. S. is added, then the solution made slightly alkaline with ammonia and $5 \mathrm{Cc}$. of glacial acetic acid added; a clear solution should result."

In the presence of more than about $0.01 \%$ of anhydrous oxalic acid a turbidity will be noticeable in 5 minutes or less. Moderate quantities of phosphoric acid and small amounts of iron do not interfere.

ACID LACTIC.

Glycerin.-The U. S. P. test is:

"Add $1 \mathrm{Cc}$. of lactic acid, in drops, to $5 \mathrm{Cc}$. of ether, shaking it after each addition; the ether solution does not become even transiently turbid."

This test will not show less than about $5 \%$ of glycerin when ether of about 0.715 sp. gr. is used. Absolute ether renders the test more delicate. It has also been noted that when sufficient glycerin is present to give a slight turbidity in the test, the turbidity will be formed when about $0.25 \mathrm{Cc}$. of the acid is added, but it disappears when one-half or all of the acid has been added.

In connection with the ether test for glycerin it might be well to mention the fact that small quantities of calcium or magnesium salts, not in excess of the amount permitted by the ash test, will also give a turbidity in the test and thus lead to an erroneous conclusion of the presence of glycerin. The test for glycerin was probably useful in the time when a chemical assay was a luxury, but now with a requirement of $85-90 \%$ acid strength and a suitable assay provided, the glycerin test could be very well omitted.

Oxalic, Phosphoric, and Tartaric Acids.-The U. S. P. test reads:

"No turbidity is produced on heating the acid with an excess of lime water."

This test is delicate to about $0.3-0.4 \%$ for oxalic acid and $0.5 \%$ phosphoric acid- 
a delicacy sufficient for U. S. P. purposes; but it will not detect tartaric acid even when it is present to the extent of 10 to $15 \%$. If a test for tartaric acid in lactic is desired, the following is suggested:

"Add 2 Cc. of potassium acetate solution ( 1 in 2$)$ to $3 \mathrm{Cc}$. of lactic acid, shake for ten to fifteen seconds several times during 20 minutes and allow to stand for 15 minutes; no turbidity is noticeable."

In the presence of more than $0.5 \%$ of tartaric acid a turbidity, due to the formation of potassium bitartrate, will be formed. Allowing the mixture to stand over night, as little as $0.3 \%$ of tartaric will yield a turbidity.

Sugar.-The U. S. P. test is delicate to about $0.05 \%$ (as sucrose).

\section{ACID NITRIC.}

Sulphuric Acid.- "Diluted with 10 volumes of distilled water, it yields no precipitate upon the addition of barium chloride T. S." (U. S. P.)

This test is inexplicit, particularly in view of the fact that the nitric acid is supposed to be of a high grade of purity. The U. S. P. does not state how much barium chloride is to be added, and since no mention is made of the time at the expiration of which the observation is to be made, it is to be assumed that 5 minutes is the time limit as in other U. S. P. tests where no specific time is set.

Using $10 \mathrm{Cc}$. of the diluted acid and $0.3 \mathrm{Cc}$. of barium chloride T. S. and observing at the end of 5 minutes, the delicacy is well over $0.1 \%$. With $1 \mathrm{Cc}$. of barium chloride the delicacy is about $0.1 \%$.

As a matter of fact, nitric acid, U. S. P., contains much less sulphate than the U.S. P. test permits. The U.S.P. test is erroneous for the reason that the acid is insufficiently diluted, with the result that the relatively high concentration of acid prevents precipitation of barium sulphate. The following test, similar to that given under Acid Hydrochloric Diluted, is suggested:

"Mix $3 \mathrm{Cc}$. of the diluted acid ( 1 to 10 by volume) with $7 \mathrm{Cc}$. of water, add $1 \mathrm{Cc}$. of barium chloride and shake well. The liquid remains clear at the end of one hour."

This test is delicate to about $0.02 \%$ sulphate.

\section{ACID PHOSPHORIC.}

Hyphophosphorous or Phosphorous Acids. -The U.S. P. test for these acids is:

"Warm $5 \mathrm{Cc}$. of diluted phosphoric acid gently and add a few drops of silver nitrate T. S.; it does not become turbid or brown."

The delicacy of this test for hypophosphorous acid is $0.007 \%$ for the diluted acid, corresponding to $0.06 \%$ for the $85-88 \%$ acid.

If, instead of a few drops, $5 \mathrm{Cc}$. of silver nitrate $\mathrm{T}$. S. is added to the acid and heated to about $80^{\circ}-90^{\circ}$, the delicacy is increased five to six times. Also, if $1 \mathrm{Cc}$. of the stronger acid is warmed and 5 drops of silver nitrate added, $0.01 \%$ hypophosphorous shows a darkening in 5 minutes.

While the U. S. P. test is sufficiently sensitive for hypophosphorous acid, it is utterly inefficient for the detection of phosphorous acid. Even when as much as $1 \%$ of this acid was present in the diluted acid, no darkening was noticed. Increasing the quantity of silver nitrate to $5 \mathrm{Cc}$. rendered the test delicate to approximately $0.02 \%$ in the diluted acid, corresponding to $0.17 \%$ in the stronger acid-a striking illustration of the effect of larger quantities of reagents on the 
sensitiveness of a test. If $1 \mathrm{Cc}$. of the $85 \%$ acid is heated with $5 \mathrm{Cc}$. of silver nitrate $\mathrm{T}$. S. in a water-bath for 5 minutes, a sensitiveness of $0.01 \%$ is attainable.

U. S. P. phosphoric acid now available is entirely free of hypophosphorous or phosphorous acids.

Nitric Acid.-The U. S. P. test reads:

"Mix equal parts of diluted phosphoric acid and sulphuric acid and after cooling add a clear crystal of ferrous sulphate; no brownish color appears around the crystal."

The sensitiveness of this test is approximately $0.03 \%$ in the diluted acid, corresponding to $0.25 \%$ in the $85 \%$ acid-an abnormally large amount of impurity permissible by the U. S. P. test. Fortunately, the presence of even a much smaller quantity of nitric in $85 \%$ phosphorous will be manifested by the odor. If the U. S. P. test be applied directly to $1 \mathrm{Cc}$. of the $85 \%$ acid, the sensitiveness is $0.03 \%$, thus reducing the permissible limit of nitrate $81 / 2$ times in the $85 \%$ acid. Longer standing than 5 minutes is very beneficial in increasing the delicacy of the test. When allowed to stand for 10-15 minutes, the sensitiveness is increased twofold.

No U. S. P. phosphoric acid now available contains as much as $0.03 \%$ of nitric acid.

In the test for nitrate in sulphuric acid, the U. S. P. directs to "Overlay the acid with a solution of ferrous sulphate." The use of solution of ferrous sulphate is preferable to adding a crystal of ferrous sulphate as directed in the test for the same impurity in phosphoric acid. When a crystal of ferrous sulphate is used, the indications, in the presence of small quantities of nitrate, are indistinct and somewhat erratic, depending on the size and shape of the crystal. With solution of ferrous sulphate indications are sharp and uniform.

Phosphates. -This test is primarily intended for alkali and possibly also for alkaline earths, but since other U. S. P. tests do not exclude aluminium, it seemed advisable to determine the sensitiveness of the phosphate test for this element also.

The U. S. P. test is described under the diluted acid as follows:

"Evaporate $20 \mathrm{Cc}$. of diluted phosphoric acid to a volume of about $4 \mathrm{Cc}$. on a water-bath. - Cool, transfer $2 \mathrm{Cc}$. to a graduated cylinder and add $6 \mathrm{Cc}$. of ether and $2 \mathrm{Cc}$. of alcohol; no turbidity appears."

In the present study the experiments were made with $2 \mathrm{Cc}$. of the $85 \%$ acid, as it was evidently not the intention of the U.S. P. when testing the stronger acid for phosphate to have it first diluted to $10 \%$ and then concentrated as described in the test. Because of the presence of less water in the $85 \%$ acid than in the acid obtained by concentration of the diluted acid, the sensitiveness of the test for phosphate is greater when made directly with the stronger acid.

Aluminium.-The delicacy of the test for aluminium is about $0.25 \% \mathrm{Al}$, corresponding to a little over $1 \%$ aluminium phosphate $\left(\mathrm{AlPO}_{4}\right)$. When the ether is added, a turbidity is produced even when less aluminium is present, but it clears up on the addition of the alcohol. Doubling the quantity of etheralcohol increases the sensitiveness of the test about two times. 
Calcium.-When calcium (Ca) is present in excess of $0.1 \%$, corresponding to nearly $0.3 \%$ calcium phosphate $\left(\mathrm{Ca}_{3}\left(\mathrm{PO}_{4}\right)_{2}\right)$, a turbidity will be produced in the test. When twice as much ether-alcohol is used, a turbidity will be produced when $20-30 \%$ less calcium is present.

Sodium.-The test is sensitive to approximately $0.15 \%$ sodium (Na) corresponding to $0.5 \%$ sodium phosphate $\left(\mathrm{Na}_{2} \mathrm{HPO}_{4}\right)$. As noted under aluminium, doubling the quantity of ether-alcohol increases the sensitiveness twofold.

Sulphuric Acid.-The delicacy of this test is approximately $0.015 \%$ for the diluted acid, corresponding to $0.13 \%$ for the $85 \%$ acid.

SULPHURIC ACID.

Lead.-The U. S. P. test for lead, requiring that "no precipitate is formed within an hour on mixing sulphuric acid with 4 or 5 volumes of alcohol," is delicate to $0.0003-0.0004 \% \mathrm{~Pb}$. When $0.0005 \% \mathrm{~Pb}$ is present, a distinct turbidity is produced within 15 to 20 minutes.

Nitric Acid.-A sensitiveness of about $0.003 \%$ is attainable by the U. S. P. test.

TARTARIC ACID.

Oxalic Acid.-The delicacy of the U. S. P. test for oxalic in tartaric acid depends on the quantity of calcium sulphate solution used, but the U. S. P. does not state how much to use.

In experiments with the U.S. P. test made with tartaric acid to which the equivalent of $1 \%$ of anhydrous oxalic acid was added and using $5 \mathrm{Cc}$. of calcium sulphate T. S. no turbidity was noticeable in 30 minutes. With $10 \mathrm{Cc}$. of calcium sulphate the same acid showed a faint turbidity in 5 minutes. When tartaric acid containing $0.8 \%$ anhydrous oxalic acid was tested with $10 \mathrm{Cc}$. of calcium sulphate T. S., a faint turbidity was noticeable in 8-10 minutes. Therefore, using $10 \mathrm{Cc}$. of calcium sulphate, a delicacy of approximately $0.8 \%$ of anhydrous oxalic acid is attainable. If the mixture is allowed to stand for a longer time, the delicacy is increased, but too long standing will cause precipitation of calcium tartrate.

If a greater degree of sensitiveness is desired, the following procedure may be used to advantage:

Five Cc. of the aqueous solution of the acid ( 1 in 10$)$ is neutralized to litmus with $10 \%$ ammonia water, then another portion of $5 \mathrm{Cc}$. of the same solution of the acid is added, the mixture well shaken, cooled to $15^{\circ} \mathrm{C}$. and filtered. The filtrate is nearly neutralized with ammonia and an equal volume of calcium sulphate solution added.

With this method the delicacy of the test will be raised to about $0.3 \%$ anhydrous oxalic acid.

Sulphuric Acid.-The sensitiveness of the U. S. P. test for this impurity is approximately $0.025 \%$.

The U.S. P. purity standards for hydrochloric acid $(31-33 \%)$, hypophosphorous $(30-32 \%)$, phosphoric $(85-88 \%)$, and sulphuric acid (93-95\%) are based on the tests for the corresponding diluted acids, the U.S. P. making the statement that, for instance, "sulphuric acid conforms to the tests for identity and purity as given under Acidum Sulphuricum Dilutum when diluted to that strength." 
The wisdom of this policy for the standardization of the stronger acids is very questionable. Very few, if any, of the users of acids purchase the diluted acids. The stronger acids are the staple of commerce. The weaker acids are made by the consumer, when required, by diluting the stronger. It would therefore seem to be more to the point to have the purity standards established for the acids which are being bought and sold-the stronger acids. If the stronger acids are pure their dilutions with distilled water must also be pure.

The stronger acids should be standardized on their own merits, and independent of the standards for the diluted acids; for, as a result of the present arrangement, acids of inferior quality will meet the U. S. P. specifications. For instance, the U. S. P. allows $0.006 \%$ of non-volatile in diluted sulphuric acid, consequently the stronger acid containing $94 \%$ of $\mathrm{H}_{2} \mathrm{SO}_{4}$ may have 9.4 times as much or $0.05 \%$ of non-volatile-a very inferior acid indeed. This condition obtains also with regard to several other impurities as has been pointed out in the discussion of the respective tests.

A summary of the delicacy of the tests considered in this paper is presented in the following table:

\begin{tabular}{|c|c|c|c|}
\hline $\begin{array}{l}\text { Substance tested. } \\
\text { Acetphenetidin... }\end{array}$ & $\begin{array}{l}\text { Impurity tested for. } \\
\text { Acetanilid ......... }\end{array}$ & $\begin{array}{l}\text { Delicacy of } \\
\text { U. S. P. test. } \\
\quad 4-5 \%\end{array}$ & $\begin{array}{c}\text { Delicacy of } \\
\text { suggested test. } \\
1 \%\end{array}$ \\
\hline Acid Acetic $\ldots \ldots \ldots \ldots \ldots$ & $\begin{array}{l}\text { Formic acid......... } \\
\text { Sulphur dioxide.... }\end{array}$ & $\begin{array}{l}1.5 \% \\
0.025 \%\end{array}$ & \\
\hline Acid Benzoic................ & . Cinnamic acid...... & $2.5 \%-3 \%$ & less than $0.5 \%$ \\
\hline Acid Citric $\ldots \ldots \ldots \ldots \ldots \ldots$ & $\begin{array}{l}\text { Oxalic.............. } \\
\text { Sulphuric.......... } \\
\text { Tartaric......... }\end{array}$ & $\begin{array}{c}\text { over } 7 \% \\
0.025 \% \\
\ldots \ldots\end{array}$ & $\begin{array}{l}0.5 \% \\
0.5 \%\end{array}$ \\
\hline Acid Hydriodic, diluted......... & 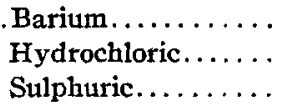 & $\begin{array}{c}0.002 \% \\
0.02 \% \\
\text { at most } 0.01 \%\end{array}$ & \\
\hline Acid Hydrobromic, diluted. . & $\begin{array}{l}\text { Barium............... } \\
\text { Sulphuric....... }\end{array}$ & $\begin{array}{l}0.005 \% \\
\text { at most } 0.01 \%\end{array}$ & \\
\hline Acid Hydrochloric.............. &. Sulphuric......... & $0.03 \%$ & \\
\hline Acid Hydrochloric, diluted........ & .Sulphuric.......... & $0.01 \%$ & \\
\hline Acid Hypophosphorous.......... & 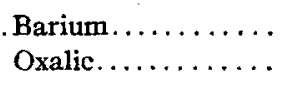 & $\begin{array}{l}0.010 \% \\
\ldots \ldots\end{array}$ & $0.03 \%$ \\
\hline Acid Hypophosphorous, diluted.. & 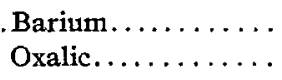 & $\begin{array}{l}0.0035 \% \\
\ldots\end{array}$ & $0.01 \%$ \\
\hline Acid Lactic... . & $\begin{array}{l}\text { Glycerin.......... } \\
\text { Oxalic............. } \\
\text { Phosphoric...... } \\
\text { Tartaric......... } \\
\text { Sugar........... }\end{array}$ & $\begin{array}{c}\text { about } 5 \% \\
0.35 \% \\
0.5 \% \\
\ldots \ldots \\
0.05 \%\end{array}$ & omit test \\
\hline Acid Nitric...$\ldots \ldots \ldots \ldots$ & . Sulphuric......... & over $0.1 \%$ & $0.02 \%$ \\
\hline Acid Phosphoric $\ldots \ldots \ldots \ldots \ldots$ & $\begin{array}{l}. \text { Hypophosphorous... } \\
\text { Nitric........... } \\
\text { Phosphates: } \\
\text { Aluminium...... } \\
\text { Calcium....... } \\
\text { Sodium........ } \\
\text { Phosphorous...... } \\
\text { Sulphuric......... }\end{array}$ & $\begin{array}{c}0.06 \% \\
0.25 \% \\
\\
0.25 \%(\mathrm{Al}) \\
0.1 \%(\mathrm{Ca}) \\
0.15 \%(\mathrm{Na}) \\
\text { over } 8 \% \\
0.13 \%\end{array}$ & $0.03 \%$ \\
\hline
\end{tabular}




\begin{tabular}{|c|c|c|c|}
\hline Substance tested. & Impurity tested for. & $\begin{array}{l}\text { Delicacy of } \\
\text { U. S. P. test. }\end{array}$ & $\begin{array}{l}\text { Delicacy of } \\
\text { suggested test. }\end{array}$ \\
\hline Acid Phosphoric, diluted. & $\begin{array}{l}\text {. Hypophosphorous... } \\
\text { Nitric............. } \\
\text { Phosphorous..... } \\
\text { Sulphuric........ }\end{array}$ & $\begin{array}{c}0.007 \% \\
0.03 \% \\
\text { over } 1 \% \\
0.015 \%\end{array}$ & $0.02 \%$ \\
\hline Sulphuric Acid........ & $\begin{array}{l}\text { Lead............. } \\
\text { Nitric........... }\end{array}$ & $\begin{array}{c}0.0003-0.0004 \% \\
0.003 \%\end{array}$ & \\
\hline Tartaric Acid.......... & $\begin{array}{l}\text { Oxalic } \ldots . . . \ldots \ldots \\
\text { Sulphuric.......... }\end{array}$ & $0.025 \%$ & $0.8 \%$ \\
\hline
\end{tabular}

Laboratory Powers-Weightman-Rosengarten Co., Phit,adelphia, Pa.

\section{THE CHEMISTRY OF MILK CURD MODIFICATION IN INFANT FEEDING.*}

BY ROBERT WOOD TERRY.

INTRODUCTION.

The specific intent of this article is an endeavor to explain in chemical terms the action of certain substances commonly used in artificial infant feeding to modify the character of milk curds. While medical literature has given this subject due consideration from a practical and clinical standpoint, the writer has been able to find but little theoretical explanation for the action of these substances. The data presented in this paper are based on experiments in vitro; the deductions and recommendations are purely theoretical and are not presented as clinical facts. For years physicians have been adding certain substances to milk to modify the character of the curds and their experience has unmistakably shown that these substances have a beneficial action. However, this knowledge has been almost wholly empirical and it is thought that the presentation of certain theoretical facts concerning the action of these substances will help to place their use on a more logical and satisfactory basis. The suggestions regarding the use of certain substances are based only on their action as milk curd modifiers. For instance, under alkalies where certain quantities of lime water are suggested, this is done with absolute disregard of the controversy as to the necessity or advisability of the addition of more calcium to the infant's food or to its effect on fat metabolism. In this connection, as Brennemann remarks, "The ultimate test of any therapeutic measure in infant feeding is the baby himself, the living, clinical, digesting baby that often laughs at our theories and weeps over our science."

\section{THE OBJECT OF MODIFICATION.}

The object of modifying the character of the milk curds is due to the great difference in the physical condition of these curds as obtained from human milk and cows' milk. The curd from human milk is flocculent and each individual curd is very small and in the aggregate resembles extremely fine cottage cheese in a watery condition. When cows' milk is coagulated under the same conditions it forms in three or four large curds. In human milk, where the curd

* Read at February meeting, Northern Ohio Branch, A. Ph. A. 